\title{
UTILIZAÇÃO DE ARGILA PARA TRATAMENTO DE ÁGUAS DE POÇOS SUBTERRÂNEOS NO MUNICÍPIO DE SOSSEGO-PB
}

\author{
Francisco Patrício de Andrade Júnior ${ }^{1}$; Ana Carolina Paiva da Silva ${ }^{1}$; Denise \\ Domingos da Silva ${ }^{1}$; Vilma Araújo da Costa ${ }^{2}$ \\ ${ }^{1}$ Universidade Federal de Campina Grande, Centro de Educação e Saúde, Lab. \\ Biocombustíveis e Química Ambiental, Unidade Acadêmica de Biologia e Química - UABQ- \\ Olho D'água da Bica S/N, CEP: 58175-000, Cuité - PB, Brasil. \\ 2 Universidade Federal do Rio Grande do Norte, Programa de Pós-Graduação em Química, \\ Instituto de Química Lagoa Nova, cep 23456-009, Natal - RN, Brasil \\ Email para correspondência: juniorfarmacia.ufcg@outlook.com
}

\section{Resumo}

A cidade de Sossego se localiza no Curimataú Paraibano e caracteriza-se por possuir uma hidrografia formada de rios temporários com cheias somente no período do inverno, sendo castigada constantemente por secas prolongadas, fazendo com que a população utilize águas subterrâneas para permitir sua subsistência havendo a necessidade, portanto, que estas águas sejam de qualidade e que sigam os padrões de potabilidade sugeridos pelo Ministério da Saúde. Diante disto, o presente estudo teve como objetivo, avaliar a qualidade físico-química de águas subterrâneas advindas de 4 poços distintos e adequar os parâmetros que se encontrassem em desacordo com os padrões de potabilidade através do método de cromatografia em coluna utilizando a argila vermelha como adsorvente. As análises físico-químicas realizadas foram: $\mathrm{pH}$, condutividade, turbidez, cloretos, alcalinidade total e dureza total. Após as análises, observou-se que somente a dureza total de todos os poços analisados se apresentou fora dos padrões de potabilidade. Entretanto, após o tratamento realizado em um dos poços, observou-se uma acentuada diminuição da dureza total de cerca de $46,7 \%$, demonstrando que a argila vermelha pode ser um promissor adsorvente para o tratamento de águas.

Palavras-chave: Controle de qualidade de águas, Adsorvente Natural, Cromatografia em Coluna.

\section{Abstract}

The city of Sossego, is located in Curimataú Paraibano and is characterized by having a hydrography formed of temporary rivers with floods only in the winter period, being punished constantly by prolonged droughts, causing the population to use groundwater to allow their subsistence, having the need, therefore, for these waters to be of quality and to follow the potability standards suggested by the Ministry of Health. The objective of this study was to evaluate the physicochemical quality of groundwater from 4 different wells and to adjust the parameters that were found to be in disagreement with the potability criteria using the column chromatography method using red clay as adsorbent. The physico-chemical 
analyzes were: $\mathrm{pH}$, conductivity, turbidity, chlorides, total alkalinity and total hardness. After the analysis, it was observed that only the total hardness of all the analyzed wells presented outside of the potability standards. However, after the treatment in one of the wells, was observed a marked decrease of the total hardness of about $46.7 \%$, demonstrating that red clay may be a promising adsorbent for water treatment.

Keywords: Water Quality Control, Natural adsorbent, Column chromatography.

\section{Introdução}

O Brasil é um país de dimensões continentais, sendo rico em recursos hídricos. Contudo, o desenvolvimento industrial, a criação de novas tecnologias, o aumento das populações e novas necessidades advindas do desenvolvimento massivo fez com que houvesse um aumento da contaminação das coleções aquáticas, causando prejuízos para a saúde humana e ambiental (ANDRADE JÚNIOR; SILVA; SILVA, 2016).

A região Nordeste do Brasil sofre com o processo de aridização e desertificação (BICUDO; TUNDISI; SCHEUENSTUHL, 2010) o que faz com que diversas populações busquem utilizar águas de poços artesianos para 0 consumo primário, geralmente, sem saber se estas estão adequadas para 0 consumo humano, sendo muitas vezes necessário utilizar métodos de purificação que nem sempre são viáveis economicamente. E entre estas cidades encontra-se o município de Sossego.

O município de Sossego, está localizado no Curimataú Paraibano, a 240 $\mathrm{km}$ da Capital do Estado, possui uma área de $300 \mathrm{~km}^{2}$ e uma hidrografia formada por rios temporários com cheias só no período do inverno (IBGE, 2010). Esta cidade, vem sofrendo constantemente com as secas prolongadas, fazendo com que a população recorra as águas subterrâneas para permitir sua subsistência.

Um levantamento realizado em 2005 neste município registrou a existência de 31 pontos d'água, todos poços tubulares, constatou-se que $47 \%$ dos pontos cadastrados são destinados ao uso doméstico primário (BRASIL, 2005). Desta forma, têm-se a necessidade de avaliar a qualidade dessas águas e, a partir daí, implementar métodos de purificação adequados.

De acordo com Costa (2012), métodos de separação por adsorção vêm substituindo os processos convencionais de purificação de efluentes devido ao avanço de estudos teóricos e experimentais que podem predizer com sucesso 
o funcionamento e condições ideais de operação de equipamentos para o uso industrial destinados à purificação de efluentes.

Buscando obter novas formas de tratamento de águas, os pesquisadores estudam alternativas viáveis para o desenvolvimento de métodos e materiais que possam contribuir ao processo de purificação. Dentre estes materiais temos as argilas que vem sendo amplamente estudadas nos últimos anos (ANDRADE JÚNIOR; SILVA; SILVA, 2016).

Além do seu baixo custo, quantidade abundante e possuir baixa capacidade de agressão a natureza, as argilas possuem propriedades como inchamento, adsorção, reológicas e coloidais e plasticidade, podendo ainda ser modificadas quimicamente permitindo com que este material seja empregado para diversos fins, dentre eles o tratamento de águas (ANDRADE JÚNIOR; SILVA; SILVA, 2016; TEXEIRA-NETO; TEXEIRA-NETO, 2009 ; PAIVA; MORALES; DÍAZ, 2008).

Dessa forma, o presente estudo teve como objetivo verificar propriedades físico-químicas de águas de alguns poços subterrâneos utilizados pela população do município de Sossego e, a partir destes resultados, promover a purificação das águas através do método de cromatografia em coluna utilizando uma argila como adsorvente.

\section{Metodologia}

\subsection{Amostragem e Coleta}

Para o processo de amostragem foram selecionados 4 poços da zona rural da cidade de Sossego-PB, todos possuindo aproximadamente 40 metros de profundidade. Em cada um dos poços foram coletadas três amostras, in loco, e em seguida armazenadas em garrafas de politereftalato de etileno (PET) e mantidas sobre refrigeração em todo o período das análises no Laboratório de Biocombustíveis e Química Ambiental do Centro de Educação e Saúde CES/ UFCG. 


\section{2 pHNa determinação das medidas do potencial hidrogeniônico presentes nas amostras, foi utilizado um peagâmetro pH 21 - Hanna.}

\subsection{Turbidez}

Os valores referentes a turbidez das amostras, foi determinado por meio de um turbidímetro modelo TB1000, em que o mesmo foi previamente calibrado com soluções padrões de 0,1 NTU, 0,8 NTU, 8 NTU, 80 NTU e 1000 NTU.

\subsection{Condutividade}

Os valores de condutividade foram determinados utilizando um condutivímetro mCA-150/Mca-150P sendo este previamente calibrado com solução padrão de cloreto de potássio $(\mathrm{KCl}) 146,9 \mu \mathrm{S} / \mathrm{cm} \pm 0,5 \%$, com uma temperatura padronizada de $25^{\circ} \mathrm{C}$.

\subsection{Alcalinidade total}

No parâmetro de alcalinidade foi utilizada a técnica clássica de volumetria de neutralização, usando como titulante o ácido sulfúrico (H2SO4) e como substância indicadora o alaranjado de metila (FUNASA, 2013)

\subsection{Dureza total}

Através da técnica de volumetria de complexação foi realizada a medida de dureza, tendo o EDTA (ácido etilenodiaminotetracético) como titulante e o Negro de Ericromio T como indicador (FUNASA, 2013).

\subsection{Cloretos}

Para determinação do teor de cloreto a técnica da volumetria de precipitação foi utilizada, através do método de Mohr, em que o agente titulante foi o nitrato de prata $(\mathrm{AgNO})$ e a solução indicadora foi o cromato de potássio ( $\mathrm{K} 2 \mathrm{CrO} 4)$ (FUNASA, 2013).

\subsection{Cromatografia em coluna}

No preparo da coluna cromatográfica, foram pesadas massas de $15,00 \mathrm{~g}$ e $30,00 \mathrm{~g}$ do adsorvente (argila vermelha). Após a pesagem, as massas foram adicionadas separadamente em béqueres de $200 \mathrm{~mL}$, sendo que a primeira massa foi lavada com água destilada 20 vezes e a segunda massa 27 vezes, 
até que a água contida nos béqueres se tornasse límpida. Em seguida, o adsorvente foi introduzido à coluna cromatográfica preparativa.

\subsection{Microscopia Eletrônica de Varredura}

As imagens da argila vermelha foram obtidas no microscópio eletrônico de varredura (MEV) Hitachi Modelo TM-3000, equipado com um sistema de microanálise química por dispersão de energia (EDS) Bruker, variando as ampliações entre 60x, 250x e 500x (SILVA et al., 2018).

\section{$3 \quad$ Resultados}

\subsection{Parâmetros físico-químicos}

A Portaria no 2.914/2011 do Ministério da Saúde, determina que a água usada para o consumo humano, deve possuir faixas de $\mathrm{pH}$ de 6,0 a 9,5, contudo as águas subterrâneas possuem valores de $\mathrm{pH}$ que geralmente podem variar entre 5,5 a 8,5 .

A partir dos experimentos realizados, encontrou-se o valor médio de $\mathrm{pH}$ para todos os poços, como podem ser observados na tabela abaixo (tabela 1):

Tabela 1. Dados referentes ao valor médio de pH encontrado nos poços.

\begin{tabular}{c|c}
\hline Poços Analisados & Valor médio de $\mathbf{~ p H} / \mathbf{S}$ \\
\hline Poço 1 & $7,30 \pm 0,016$ \\
Poço 2 & $7,21 \pm 0,016$ \\
Poço 3 & $7,96 \pm 0,050$ \\
Poço 4 & $7,60 \pm 0,010$ \\
\hline
\end{tabular}

Fonte: Dados da pesquisa.

Levando em consideração os parâmetros de potabilidade é possível perceber que todos os poços estão dentro dos padrões de normalidade para o quesito $\mathrm{pH}$, encontrando-se como menor e maior valores: 7,21 (poço 2) e 7,96 (poço 3), respectivamente. Tais resultados divergiram parcialmente dos dados obtidos em lbiporã-PR em que o valor de $\mathrm{pH}$ foi superior a 8,5 em alguns poços (CORCÓVIA; CELLIGOI, 2012).

Os valores de $\mathrm{pH}$ obtidos foram interessantes, uma vez que todas as águas apresentaram pH básico. De acordo com Castro et al., (2014) águas subterrâneas com pH ácido, são um mau indicativo, já que pode estar relacionado a contaminação por resíduos industriais. Ademais, $\mathrm{O} \mathrm{pH}$ interfere 
diretamente na capacidade de adsorção da argila empregada. Se muito baixo, pode causar colapso da estrutura e interferir no processo de adsorção.

Em relação, a condutividade elétrica, os valores médios podem ser observados na tabela abaixo (tabela 2):

Tabela 2. Dados dos valores médios da condutividade.

\begin{tabular}{c|c}
\hline Poços Analisados & $\begin{array}{c}\text { Valor médio da condutividade } \\
\left(\mathbf{m S . c m} \mathbf{-}^{-} \text {) } / \mathbf{S}\right.\end{array}$ \\
\hline Poço 1 & $6,37 \pm 0,025$ \\
Poço 2 & $3,82 \pm 0,040$ \\
Poço 3 & $5,03 \pm 0,095$ \\
Poço 4 & $5,25 \pm 0,078$ \\
\hline
\end{tabular}

Fonte: Dados da pesquisa.

Tais resultados divergem dos encontrados em águas de poços do município de lbiporã-PR, uma vez que, todas as amostras apresentaram condutividade $<0,5{\mathrm{mS} . \mathrm{cm}^{-1}}^{-1}$ (CORCÓVIA; CELLIGOI, 2012).

O Ministério da Saúde não apresenta valores determinados para 0 parâmetro condutividade elétrica. Entretanto, Castro et al. (2014) afirmam que este é um excelente parâmetro indicador de ação antrópica na alteração da qualidade ambiental dos recursos hídricos. Dessa forma, a FUNASA (2014) destaca que as águas naturais devem apresentar teores de condutividade na faixa de 10 a $100 \mu \mathrm{S} / \mathrm{cm}$, entretanto em ambientes poluídos por esgotos domésticos ou industriais, os valores podem chegar a $1.000 \mu \mathrm{S} / \mathrm{cm}$.

Sobre a alcalinidade, o Ministério da Saúde não possui portarias específicas que permitam avaliar se os valores para este parâmetro estão adequados ao consumo humano. Os valores encontrados podem ser observados na tabela 3.

Tabela 3. Valores médios da alcalinidade total.

\begin{tabular}{c|c}
\hline Poços Analisados & Valor médio da alcalinidade total(mg. $\left.\mathbf{L}^{\mathbf{1}}\right) / \mathbf{S}$ \\
\hline Poço 1 & $326,66 \pm 0,23$ \\
Poço 2 & $306,00 \pm 0,20$ \\
Poço 3 & $350,00 \pm 0,10$ \\
Poço 4 & $344,66 \pm 0,25$ \\
\hline
\end{tabular}


Tais resultados diferem dos encontrados no município de Manaus-AM em que os valores de alcalinidade variaram entre 3,8 a 4,8 mg.L-1 (ARAÚJO; HIPÓLITO; WAICHMAN, 2013).

Segundo a FUNASA (2014) a maioria das águas naturais devem apresentar valores de alcalinidade na faixa de 30 a $500 \mathrm{mg} / \mathrm{L}$ de $\mathrm{CaCO}_{3}$, deste modo, os valores de alcalinidade encontrados estão adequados, uma vez que, houve uma variação para este parâmetro de 306,00 mg.L-1 $^{1}$ (poço 2) a 350,00 mg.L-1 (poço 3).

Em relação a turbidez, de acordo com a Portaria oㅡ 2.914/2011 do Ministério da Saúde para águas subterrâneas com desinfecção, o limite máximo para qualquer amostra pontual deve ser de 5 NTU.

Tabela 4. Valores médios de turbidez para os poços analisados.

\begin{tabular}{c|c}
\hline Poços Analisados & Valor médio da turbidez (NTU)/S \\
\hline Poço 1 & $0,056 \pm 0,019$ \\
Poço 2 & $0,250 \pm 0,020$ \\
Poço 3 & $0,530 \pm 0,010$ \\
Poço 4 & $0,250 \pm 0,015$ \\
\hline
\end{tabular}

Fonte: Dados da pesquisa.

A partir dos resultados encontrados (tabela 4) é observado que todos os poços se apresentaram adequados ao consumo humano. Estes resultados corroboram com o estudo de Daneluz \& Tessaro (2015), que observaram que todos os poços investigados na região sudoeste do Paraná apresentavam turbidez compatível com os parâmetros de potabilidade

Sobre cloretos, as águas podem ser consumidas por seres humanos, desde que haja até $250 \mathrm{mg} \cdot \mathrm{L}^{-1}$ destes componentes presentes nas amostras analisadas, estando assim, todas as águas estudadas compatíveis com este parâmetro, como observado na tabela 5 .

Tabela 5. Valores do teor de cloreto para os poços analisados.

\begin{tabular}{c|c}
\hline Poços Analisados & Valor médio de cloretos $\left.\mathbf{( m g} \cdot \mathbf{L}^{-1}\right)$ \\
\hline Poço 1 & $2,15 \pm 0,26$ \\
Poço 2 & $1,17 \pm 0,00$ \\
Poço 3 & $1,66 \pm 0,32$ \\
Poço 4 & $1,69 \pm 0,11$ \\
\hline
\end{tabular}

Fonte: Dados da pesquisa. 
Tal descoberta é importante, uma vez que uma água rica em cloretos pode ser prejudicial a pessoas portadoras de afecções cardíacas ou renais (HELLER; PÁDUA, 2006).

$\mathrm{Em}$ relação à dureza, esta é expressa $\mathrm{em} \mathrm{mg} / \mathrm{L}$ de equivalente em carbonato de cálcio $\left(\mathrm{CaCO}_{3}\right)$ e pode ser classificada em mole ou branda: $<50$ $\mathrm{mg} / \mathrm{L}$ de $\mathrm{CaCO}_{3}$; dureza moderada: entre $50 \mathrm{mg} / \mathrm{L}$ e $150 \mathrm{mg} / \mathrm{L}$ de $\mathrm{CaCO}_{3}$; dura: entre $150 \mathrm{mg} / \mathrm{L}$ e $300 \mathrm{mg} / \mathrm{L}$ de $\mathrm{CaCO}_{3}$; e muito dura: $>300 \mathrm{mg} / \mathrm{L}$ de $\mathrm{CaCO}_{3}$ (FUNASA, 2014).

Tabela 6. Valores de dureza total para os poços analisados.

\begin{tabular}{c|c}
\hline Poços Analisados & Valor médio de cloretos $\left.\mathbf{( m g} \cdot \mathbf{L}^{\mathbf{- 1}}\right)$ \\
\hline Poço 1 & $4278,16 \pm 0,17$ \\
Poço 2 & $2514,26 \pm 0,50$ \\
Poço 3 & $1934,34 \pm 0,40$ \\
Poço 4 & $2037,83 \pm 0,36$ \\
\hline
\end{tabular}

Fonte: Dados da pesquisa.

Todos os poços estudados apresentam águas muito duras o que pode ser normal, uma vez que as águas subterrâneas, devido o processo de lixiviação, se apresentam mais duras que as águas superficiais (SILVA, 2015).

Estes resultados diferem dos encontrados em Manaus-MA, em que os poços analisados apresentaram águas classificadas como moles ou brandas (ARAÚJO; HIPÓLITO; WAICHMAN, 2013).

A Portaria no 2.914/2011 do Ministério da Saúde, estabelece para o parâmetro de dureza total o teor máximo de até $500 \mathrm{mg} / \mathrm{L}$ em termos de $\mathrm{CaCO}_{3}$ para a água potável. Com base neste parâmetro nenhum dos poços mostrouse adequado ao consumo humano.

Levando em consideração os valores da dureza total que estão em desacordo aos padrões de potabilidade, foi selecionado o poço que apresentou maior dureza (poço 1) para a realização do tratamento utilizando a argila vermelha como adsorvente.

Antes do tratamento com a argila, a dureza total era de $4278,16 \mathrm{mg} \cdot \mathrm{L}^{-1} \mathrm{e}$ logo após o tratamento, utilizando $15 \mathrm{~g}$ de massa, observou-se uma acentuada diminuição (46,7\%), apresentando dureza total de 2334,09 mg. L-1. 
Resultados distintos foram encontrados por Zadinelo (2014) que ao utilizar a argila esmectita para o tratamento de efluentes sintéticos e aquícolas, observou o aumento da dureza das amostras.

Estes diferentes resultados retratam que a atividade das argilas irão depender principalmente das amostras analisadas, dos argilominerais que constituem a argila.

A diminuição da dureza observada pode ter se dado devido a capacidade de troca catiônica (CTC) presentes em algumas argilas. De acordo com Raij (1969) CTC é uma característica físico-química que indica a quantidade de íons positivos que um solo é capaz de reter em determinas condições e permutar por quantidades estequiometricamente equivalentes de outros íons do mesmo sinal. Em relação a argila vermelha essa troca, pode ter ocorrido através dos íons cálcio e magnésio, uma vez que houve a diminuição da dureza.

De acordo com a Ronquim (2010) em razão da superfície eletricamente carregada que apresentam as argilas coloidais, fazem com que os íons e moléculas polarizadas sejam atraídos e liguem-se a estes componentes de forma reversível. Os argilominerais, as substâncias húmicas e os óxidos de ferro e alumínio possuem determinada superfície de troca e são os principais coloides responsáveis pela capacidade de troca de cátion dos solos sob condições tropicais.

$\mathrm{Na}$ tentativa de potencializar os resultados, uma segunda amostra do poço 1 foi colhida e mais uma vez sua dureza total foi determinada, porém utilizando $30 \mathrm{~g}$ do adsorvente.

Após a determinação da dureza total da amostra 2 para o poço 1, foi observado que a mesma também se apresentou em desconformidade com 0 padrão de potabilidade em relação ao parâmetro dureza total, uma vez que esta amostra apresentou 4550,99 mg. $\mathrm{L}^{-1} \mathrm{CaCO}_{3}$. Em seguida, depois do tratamento desta amostra utilizando a argila vermelha, verificou-se que houve uma diminuição na dureza total, chegando a conter $3883,49 \mathrm{mg}$. $\mathrm{L}^{-1}$ o que indica que com a massa de $30 \mathrm{~g}$ também houve atividade adsorvente observada, porém com valores menores em relação a atividade adsortiva constatada na utilização de $15 \mathrm{~g}$, que pode ter se dado devido a presença de - 
interferentes presentes na segunda amostra, ou até mesmo devido a saturação do material, contudo mais estudos precisam ser realizados.

\subsection{Microscopia eletrônica de varredura}

Nas argilas, a microscopia eletrônica de varredura (MEV) é bastante utilizada para a identificação dos cristais individuais dos minerais argilosos, permitindo observar que o mesmo argilomineral pode apresentar variações morfológicas. Além disso, permite avaliar a dimensão das partículas ou cristais e detectar possíveis impurezas (GOMES, 1988).

Verifica-se nas massas argilosas a presença de partículas finas e aglomerados de perfil irregular, no entanto alterações morfológicas não puderam ser observadas nas argilas antes (Figura 1) e depois (Figura 2) do processo de adsorção.

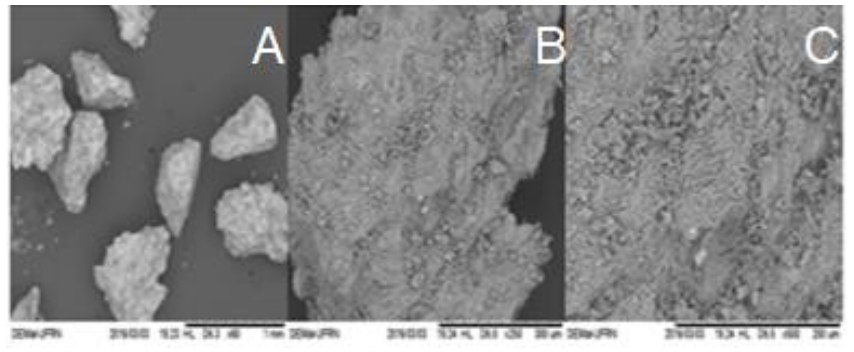

Figura 1. Micrografia eletrônica de varredura da argila vermelha antes da adsorção da amostra. (A) com ampliação de 60x (B) 250x e (C) 500x.

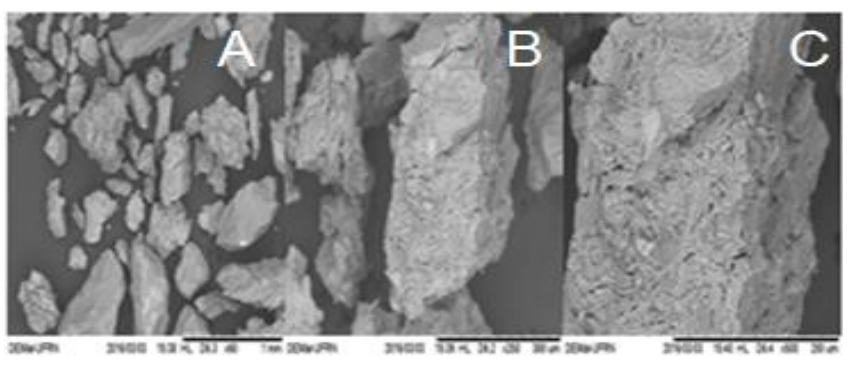

Figura 2. Micrografia eletrônica de varredura da argila vermelha depois da adsorção da amostra. (A) com ampliação de 60x (B) 250x e (C) 500x.

\section{Conclusão}

Os poços estudados apresentaram-se dentro dos padrões estabelecidos pelo Ministério da Saúde para todos os parâmetros analisados, com exceção do 
parâmetro dureza total, em que todos os poços se mostraram em desconformidade, necessitando de tratamento.

Ao realizar o tratamento das águas com a argila vermelha, este material mostrou ser promissor, uma vez que, permitiu uma diminuição considerável da dureza total de um dos poços estudados, após o tratamento por meio da cromatografia em coluna, sendo portanto importante estudos mais específicos para se ter um maior conhecimento das características e potencialidades deste adsorvente.

\section{Referências}

ANDRADE JÚNIOR, F. P.; SILVA, A. C. P.; SILVA, D. D. Aplicações de argilas como adsorvente em prol dos recursos hídricos. Revista Educação, Ciência e Saúde, v.3, n.1, p.18.38, 2016.

BICUDO, C.E.M.; TUNDISI, J.G.; SCHEUENSTUHL, M.C.B. Águas do Brasil: análises estratégicas. São Paulo: Instituto de Botânica, 2012.

BRASIL. Ministério da Saúde. Portaria n. 2.914/2011, de 12 de dezembro de 2011. Dispõe sobre os procedimentos de controle e de vigilância da qualidade da água para consumo humano e seu padrão de potabilidade. Brasília: SVS, 2011.

BRASIL. Ministério de Minas e Energia. Projeto cadastro de fontes de abastecimento por água subterrânea estado da Paraíba: Diagnóstico do município de Sossego. 2005. Disponível em: < http://www.cprm.gov.br/publique/?tpl=home >. Acesso em: 27 Abr. 2017.

CASTRO, J. S. O et al. Potabilidade das águas subterrâneas para o consumo humano na área do polo industrial de Barcarena-Pará. Enciclopédia Biosfera, v.10, n.19, p.2921-2934, 2014.

CORCÓVIA, J. A.; CELLIGOI, A. Avaliação preliminar da qualidade da água subterrânea no município de lbiporã-PR. Revista de estudos ambientais, v.14, n.2, p.39-48, 2012.

COSTA, J. M. Desenvolvimento de nanoestruturas adsorvente de argilas para tratamento de efluentes contendo compostos orgânicos do tipo BETX. 2012. 94 f. 
Dissertação (Mestrado em Gestão e Tecnologia Industrial) - Faculdade tecnologia SENAI CIMATEC, Salvador, 2012.

FUNASA. Fundação Nacional de Saúde. Manual de controle de qualidade da água para técnicos que trabalham em etas. Brasília: FUNASA, 2014.

FUNASA. Fundação Nacional de Saúde. Manual prático de análise de água. Brasília: FUNASA, 2013.

HELLER, L.; PÁDUA, V. L. Abastecimento de água para consumo humano. Belo Horizonte: Editora UFMG, 2006.

IBGE. Instituto Brasileiro de Geografia e Estatística. Histórico: Sossêgo Paraíba - PB. 2010 Disponível em: < http://biblioteca.ibge.gov.br/bibliotecacatalogo.html?view=detalhes\&id=3985>. Acesso em: 27 Abr. 2017.

PAIVA, L. B; MORALES, A. R; DÍAZ, F. R. V. Argilas organofílicas: características, metodologias de preparação, compostos de intercalação e técnicas de caracterização. Cerâmica, v.54, n.330, p.213-226, 2008

RAIJ, B. V. A capacidade de troca de cátions das frações orgânica e mineral em solos. Bragantia, v.28, n.8, p.85-112,1969

RONQUIM, C. C. Conceitos de fertilidade do solo e manejo adequado para as regiões tropicais. Campinas: Embrapa Monitoramento por Satélite, 2010.

SILVA, A. C. P. et al. Aplicação da semente de acerola (MALPIGHIA EMARGINATA) como adsorvente natural para abrandamento de águas subterrâneas. Tchê Química, v.29, n.15, p.49-55, 2018.

SILVA, L. P. Hidrologia: engenharia e meio ambiente. Rio de Janeiro: Elsevier, 2015.

TEXEIRA-NETO, E.; TEXEIRA-NETO, A. A. Modificação Química de Argilas: Desafios Científicos e Tecnológicos para obtenção de novos produtos com maior valor agregado. Química Nova, v.32, n.3, p.809-817, 2009. 
ZADINELO, I. V. Eficiência de argilas esmectitas na adsorção da amônia de efluentes sintéticos e aquícolas e, sua aplicação sob a influência de diferentes temperaturas durante o cultivo do jundiá ( Rhamdia quelen ). $2014.65 \mathrm{f}$. Dissertação ( Mestrado em Aquicultura e Desenvolvimento Sustentável) Universidade Federal do Paraná. Palotina, 2014.

\section{Agradecimentos}

Ao CNPq pelo fornecimento da bolsa e ao Labpemol/UFRN pela colaboração com o estudo. 